\title{
ANALISIS PENGARUH LOGISTICS SERVICE QUALITY TERHADAP KEPUASAN DAN LOYALITAS PELANGGAN PADA PERUSAHAN LOGISTIK JALUR NUGRAHA EKAKURIR (JNE)
}

\author{
Shinta Wahyu Hati, 1) Aisyah Juliati ${ }^{2)}$ \\ * Politeknik Negeri Batam \\ Program Studi Administrasi Bisnis Terapan \\ Parkway Street, Batam Centre, Batam 29461, Indonesia \\ E-mail:shinta@polibatam.ac.id.ac.id \\ \# Politeknik Negeri Batam \\ Program Studi Akuntansi Manajerial \\ Parkway Street, Batam Centre, Batam 29461, Indonesia \\ E-mail: aisyahjuliatioffical@gmail.com
}

\begin{abstract}
Abstrak
Ujung tombak dalam e-commerce adalah jasa penyedia logistik itu sendiri yang mempunyai peranan penting dalam perkembangan suatu $e$-commerce. Para penyedia jasa logistik harus sangat memperhatikan kualitas atas jasa penyedia logistik yang diberikan karena aspek ini langsung akan berdampak pada rasa kepuasan dan tingkat loyalitas pelanggan. Untuk dapat mengukur tingkat kepuasan dari pelanggan perlu dilakukan agar mampu meningkatkan seberapa jauh kualitas pelayanan guna menciptakan loyalitas pelanggan. Penelitian ini bertujuan untuk mengetahui pengaruh Logistics Service Quality terhadap kepuasan dan loyalitas pelanggan. Metode penelitian menggunakan pendekatan metode kuantitatif. Penelitian ini menggunakan data primer yang berbentuk kuesioner. Penarikan sampel penelitian menggunakan metode purposive sampling yang mendapat 113 sampel dari mahasiswa/i wilayah Batam. Teknik penarikan sampel dengan kriteria mahasiswa/i yang mempunyai online shopping dan berada dilingkup jurusan manajemen bisnis. Teknik pengolahan data menggunakan PLSSEM (Partial Least Square-Structural Equation Model). Hasil penelitian ini konsisten dengan penelitian sebelumnya, yang menyatakan bahwa Logistics Service Quality berpengaruh positif dan signifikan terhadap tingkat kepuasan pelanggan dalam penggunaan layanan jasa. Logistics Service Quality berpengaruh positif dan signifikan terhadap tingkat loyalitas pelanggan. Kepuasan pelanggan berpengaruh positif dan signifikan terhadap tingkat loyalitas pelanggan
\end{abstract}

Kata Kunci: Logistics Service Quality (LSQ), E-Commerce, Kepuasan, Loyalitas.

\begin{abstract}
The cutting edge in e-commerce is the logistics service provider itself which has an important role in the development of an e-commerce. The logistics service providers should be very attentive to the quality of the top logistics service provider is given because this aspect will directly impact on the sense of satisfaction and customer loyalty levels. To be able to measure the level of satisfaction of customers ' needs to be done to improve how far the quality of service in order to create customer loyalty. This research aims to know the influence of Logistics Service Quality towards customer satisfaction and loyalty. The method research of using quantitative methods approach. The research of using primary data in the form of a questionnaire. Withdrawal of samples of research 240 | Jurnal Akuntansi, Ekonomi dan Manajemen Bisnis | Vol. 7 No.2, December 2019, 240-249 | E-ISSN: $2548-9836$
\end{abstract}


using the method of purposive sampling who got 113 samples of the student area of Batam. Engineering sample withdrawal criteria students have online shopping and located in the Department of business management. Data processing techniques using PLSSEM (Partial Least Square-Structural Equation Modeling). The results of this study are consistent with previous research, which states that Service Logistics Quality is positive and significant to the level of customer satisfaction in the use of services. Logistic Service Quality is positive and significant to the level of customer loyalty. Positive and significant customer satisfaction on the level of customer loyalty

\section{Keyword: Logistics Service Quality (LSQ), E-Commerce, Satisfaction, Loyalty}

\section{PENDAHULUAN}

Perdagangan adalah salah satu faktor pertumbuhan ekonomi, baik itu perdagangan tradisional dimana bertemunya penjual dan pembeli disuatu tempat lalu melakukan transaksi jual beli maupun perdagangan elektronik atau yang lebih dikenal e-commerce. Perdagangan e-commerce yaitu proses transaksi antara penjual dan pembeli dilakukan melalui sistem elektronik seperti internet, website dan lainnya. Faktor utama dalam melakukan perdagangan e-commerce yang mendukung suatu perdagangan itu sendiri adalah diperlukannya jasa transportasi yang melayani proses pengiriman barang.

Seiring dengan tingginya kebutuhan masyarakat atas jasa pengiriman barang, menjadi sebuah peluang bagi beberapa pelaku bisnis logistik. Peran logistik Di negara dengan tren e-commerce yang berkembang secara pesat seperti Singapore dan Indonesia, sarana logistik semakin menjadi tulang punggung yang sangat krusial untuk perkembangan pasar.

Logistik secara umum merupakan bagian dari proses rantai pasok yang merencanakan, menerapkan, serta mengontrol penyimpanan dan aliran barang, jasa, dan segala macam informasi yang terkait dari titik pasokan sampai ke titik permintaan untuk dapat memenuhi permintaan pelanggan.

Saat pemilihan strategi untuk menjadikan sebuah perusahaan maju dalam dunia perdagangan $e$ commerce mereka harus memfokuskan sistem kualitas pelayanan atas logistik tersebut (Logistics Service Quality ) dan kepuasan dari para pelanggan, agar menjadikan alat evaluasi bagi kemajuan perusahaan di masa yang akan datang dan akan berdampak pada tingkat loyalitas dari pelanggan.

Diperlukan hubungan penilaian terhadap kualitas pelayanan dan kepuasan pelanggan untuk mencapai dan memperoleh rasa loyalitas dari pelanggan dalam melaksanakan perdagangan elektronik atau e-commerce. Definisi dari kualitas pelayanan tersebut adalah seberapa jauh perbedaan antara harapan dan kenyataan para pelanggan atas layanan yang mereka terima.

Perusahaan logistik yang saat ini berkembang dan melayani pengiriman riel adalah JNE. JNE adalah perusahan di bidang pengiriman dan logistik. Nama resmi JNE adalah Jalur Nugraha Ekakurir .

Perusahaan JNE dikenal sebagai salah satu perusahaan logistik pengiriman barang yang bisa dikatakan masih mendominasi pasar di Indonesia. Selain mendominasi, perusahaan JNE juga menjadi perusahaan logistik yang paling terkenal di Indonesia dan mendapatkan penghargaan kepuasan pelanggan yang bergengsi di tahun 2019 (www.moneysmart.id)

Seiring dengan pertumbuhan e-commerce belanja online dan promosi usaha kecil dari start-up JNE hadir mampu memberikan solusi pengiriman cepat. Salah satu konsumen sebagai pelanggan potensial adalah mahasiswa. Mahasiswa saat ini sebagai generasi milinieal sudah sangat adaptif dengan penggunaan $e$-commerce pada situs belanja, dan di situs belanja tersebut juga menyediakan pilihan jasa pengiriman logistik yang transaksinya menggunakan e-commerce, tidak terkecuali adalah mahasiswa di Kota Batam yang juga menggunakan jasa pengiriman logistik JNE kebutuhannya dirinya atau untuk berwirausaha.

Rumusan masalah dalam penelitian ini adalah sejauhmana pengaruh Logistics Service Quality terhadap Kepuasan Pelanggan dan loyalitas pelanggan JNE. Tujuan penelitian ini adalah mengetahui dan menganalisis pengaruh pengaruh Logistics Service Quality terhadap Kepuasan Pelanggan dan loyalitas pelanggan JNE. Manfaat penelitian ini memberikan masukan pada perusahaan jasa logistik JNE untuk memperbaiki layanan jasanya dan untuk meningkatkan kepuasan pelanggan.

\section{KAJIAN PUSTAKA}




\section{Logistics Service Quality (LSQ)}

Menurut Wickof dalam Tjiptono (2007), kualitas jasa merupakan tingkat keunggulan (excellence) yang diharapkan dan pengendalian atas keunggulan tersebut untuk memenuhi keinginan pelanggan. Sedangkan menurut parassuraman dalam Rambat Lupiyoadi (2001), service quality dapat didefinisikan sebagai seberapa jauh perbedaan antara kenyataan dan harapan pelanggan atas layanan yang mereka peroleh. Sejak pertengahan tahun 1980an, kualitas layanan telah menjadi prioritas dalam penelitian pemasaran dan logistik, yang berjalan paralel pada kualitas, kualitas manajemen dan kepuasan pada perusahaan (Saura et al., 2008).

Kualitas Layanan Logistik adalah target yang pelanggan rasakan. Kualitas layanan tidak dapat ditentukan hanya oleh perusahaan, harus memenuhi permintaan pelanggan dan harapan. Berdasarkan penelitian yang dilakukan oleh (Ho, et al., 2012) pengukuran dari Logitics Service Quality terbagi dalam 4 dimensi yaitu:

a) Timeliness (Ketepatan Waktu)

b) Accuracy of Order (Ketepatan Order)

c) Quality of Information (Kualitas Informasi)

d) Quality of Contact Personnel (Kualitas Kontak Personel)

e) Order Discrepancy Handling (Penanganan Masalah)

\section{Kepuasan Pelanggan}

Menurut Kotler (2003), kepuasan pelanggan adalah perasaan senang atau kecewa seseorang yang muncul setelah membandingkan antara persepsi atau kesan terhadap kinerja atau hasil suatu produk dan harapan-harapannya. Jadi, kepuasan merupakan fungsi dari persepsi atau kesan atas kinerja dan harapan. Jika kinerja berada dibawah harapan maka pelanggan tidak puas. Jika kinerja memenuhi harapan maka pelanggan akan puas. Jika kinerja melebihi harapan maka pelanggan akan amat puas atau senang. Kunci untuk menghasikan kesetian pelanggan adalah memberikan nilai pelanggan yang tinggi.

\section{Loyalitas Pelanggan}

Menurut Hasan (2008), bahwa loyalitas pelanggan adalah pelanggan yang hanya tidak membeli ulang suatu barang dan jasa misalnya dengan merekomendasikan orang lain untuk membeli. Loyalitas yang ditunjukkan oleh pelanggan biasanya didukung faktor kepuasan pelanggan. Semakin besar tingkat kepuasan pelanggan terhadap layanan yang diberikan suatu perusahaan, maka semakin besar pula tingkat loyalitas pelanggan terhadap perusahaan tersebut. Hal tersebut dikarenakan pelanggan tersebut telah merasa nyaman dan puas atas pelayanan yang diberikan pada suatu perusahaan penyedia dan sebaiknya rasa loyalitas yang diberikan kepada suatu perusahaan juga didukung oleh faktor lain selain dari sekedar pelayanan saja.

\section{KERANGKA PEMIKIRAN}

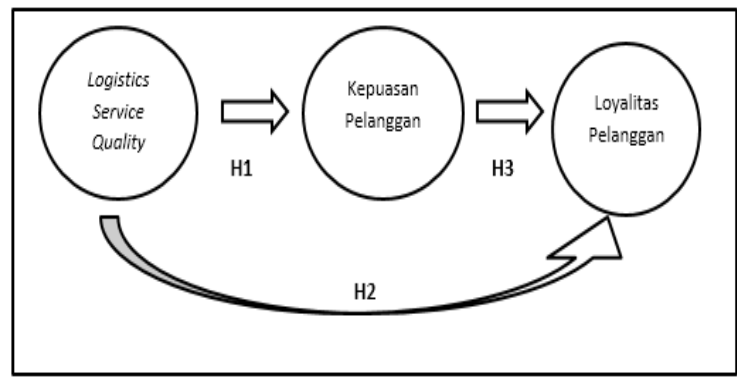

Gambar 1. Model pengaruh Logistic Service Quality terhadap kepuasan dan loyalitas pelanggan.

Pada penelitian ini mengadopsi hasil penelitian terdahulu yang melandasi penelitian ini dalam pengembangan hipotesisnya. Penelitian terdahulu tersebut adalah menurut Adrian, Kamer dan Alexandru (2013), Leva, Arturas, dan Michail (2014), Milorad dan Milan (2016), Shashank et al. (2011), Shpetim Cerri (2012)

\section{Pengaruh Logistics Service Quality terhadap Kepuasan Pelanggan}

Berdasarkan teori Logistik dan teori SERVQUAL yang didapatkan, maka dapat disimpulkan bahwa yang dimaksud Logitics Service Quality adalah suatu upaya yang dilakukan perusahaan dalam mengantisipasi kebutuhan dan keinginan akan barang dan jasa yang dibutuhkan konsumen serta mengoptimalkan pengelolaan jaringan barang dan jasa agar dapat sampai ke tangan konsumen secara tepat waktu sehingga terjadi kepuasan konsumen atau harapan konsumen terpenuhi. 
Pengalaman seorang pelanggan bisa menjadi tolak ukuran yang relevan untuk menjadikan sebuah perusahaan berkembang lebih baik lagi dari sebelumnya dan dapat disimpulkan bahwa Logistics Service Quality yang baik yang diberikan kepada pelanggan akan membuat pelanggan merasa puas akan pelayanan jasa JNE tersebut. Berdasarkan uraian di atas maka dapat disimpulkan hipotesis yaitu:

H1: Logistics Service Quality secara positif berpengaruh terhadap Kepuasan Pelanggan

\section{Pengaruh Logistics Service Quality terhadap Loyalitas Pelanggan}

Dalam menilai tingkat Logistics Service Quality (LSQ) mempunyai indikitor yang bisa diukur untuk mengetahui hasil atau relasi dengan variabel yang dipengaruhi. Jika dalam layanan yang dilakukan kepada pelanggan dapat mempengaruhi repurchase dari pelanggan maka dapat dinyatakan terdapat nilai loyalitas pada pelanggan tersebut karena mereka melakukan pembelian kembali secara terus-menerus pada satu perusahaan logistik yang sangat memperhatikan dalam Logistics Service Quality.

Menurut Supriyatmini (2005), loyalitas merupakan kesetiaan pelanggan terhadap penyedia jasa yang telah memberikan pelayanan kepadanya. Kepuasan pelanggan dari pembelian atau penggunaan jasa perusahaan yang dirasakan pelanggan menjadikan pengalaman bagi perusahaan untuk mengembangkan kemampuan dan kualitas servis pelayanan logistik. Loyalitas didefinisikan sebagai perilaku pelanggan dimana mereka berulang kali membeli produk atau jasa merk atau perusahaan tertentu. Maka loyalitas pelanggan adalah aset tidak berwujud yang penting bagi perusahaan, semakin tinggi tingkat kepuasan maka semakin tinggi loyalitas pelanggan terhadap perusahaan pelayanan logistik tersebut.

Dengan demikian, dapat disimpulkan hipotesis sebagai berikut:

\section{H2: Logistics Service Quality secara positif berpengaruh terhadap Loyalitas Pelanggan.}

\section{Pengaruh Kepuasan Pelanggan terhadap Loyalitas Pelanggan}

Menurut Supriyatmini (2005), loyalitas merupakan kesetian pelanggan terhadap penyedia jasa yang telah memberikan pelayanan kepadanya. Kepuasan pelanggan dari pembelian atau pengguna jasa perusahaan yang dirasakan pelanggan menjadikan pengalaman bagi perusahaan untuk mengembangkan kemampuan dan kualitas pelayanan jasa perusahaan logistik tersebut.

Lebih lanjut Supriyatmini menjelaskan Loyalitas didefinisikan sebagai perilaku pelanggan dimana mereka berulang kali membeli produk atau jasa merk atau perusahaan tertentu. Loyalitas adalah aset tidak berwujud yang penting bagi perusahaan, semakin tinggi tingkat kepuasan maka akan semakin tinggi loyalitas pelanggan terhadap perusahaan logistik. Jika perusahaan ingin menyimpan sukses terus-menerus maka harus meningkatkan tingkat retensi pelanggan dan membuat pelanggan loyal atas merk suatau perusahaan. Dengan demikian, hipotesis yang dikembangkan dari uraian di atas yaitu:

\section{H3: Kepuasan Pelanggan secara positif berpengaruh terhadap Loyalitas Pelanggan}

\section{METODE PENELITIAN}

\section{Jenis Penelitian}

Metode penelitian yang digunakan dalam penelitian ini adalah pendekatan kuantitatif. Menurut Sugiyono (2016) Metode kuantitatif dapat diartikan sebagai metode penelitian yang berlandaskan pada filsafat positivisme digunakan untuk meneliti populasi atau sampel tertentu, pengumpulan data menggunakan instrumen penelitian analisis data bersifat kuantitatif/statistik dengan tujuan untuk menguji hipotesis yang telah ditetapkan.

\section{Populasi dan Sampel}

Populasi dalam penelitian ini adalah mahasiswa bidang studi manajemen. Penentuan jumlah sampel dari populasi dalam penelitian ini adalah menggunakan rumus slovin dengan taraf kesalahan 5\%. Dari per-hitungan dapat diketahui sampel minimal dalam penelitian ini adalah sebanyak 113 responden. Penelitian ini menggunakan jenis data primer.

\section{Teknik Pengumpulan Data}


Teknik pengumpulan data menggunakan kuesioner. Menurut Sugiyono (2017) kuesioner merupakan teknik pengumpulan data dengan cara memberi seperangkat pertanyaan atau pernyataan tertulis kepada responden untuk menjawabnya.

\section{METODE ANALISIS DATA}

Teknik analisis data yang digunakan untuk menguji hipotesis adalah analisis PLS-SEM (Partial Least Squares-Structural Equation Modeling). PLS sebagai model prediksi tidak mengasumsikan distribusi tertentu untuk mengestimasi parameter dan memprediksi hubungan kausalitas, karena teknik parametrik untuk menguji signifikansi parameter tidak diperlukan, dan model evaluasi untuk prediksi bersifat non-parametrik. Evaluasi model PLS

dilakukan dengan mengevaluasi Outer Model dan Inner Model (Jogiyanto, 2011)

\section{Uji Validitas Konstruk}

Uji validitas konstruk secara umum dapat diukur dengan parameter skor loading di model penelitian (Rule of Thumbs > 0,7), namun untuk penelitian pada tahap awal jika terdapat nilai yang berada di atas 0,5 atau 0,6 masih dianggap memadai dan bisa digunakan (Ghozali, 2014) dengan menggunakan parameter Average Variance Extracted (AVE) >0, 50 dan Communality > 0, 50. Adapun hasil output korelasi antar indikator dengan konstruk lengkap dapat dilihat pada tabel di bawah ini:

\section{Tabel 1}

\section{Faktor Loading Indikator}

\begin{tabular}{|c|c|c|c|c|}
\hline KONSTRUK & $\mathbf{N}$ & ITEM & INDIKATOR & $\begin{array}{l}\text { FAKTOR } \\
\text { LOADING }\end{array}$ \\
\hline \multirow{2}{*}{$\begin{array}{l}\text { Information quality } \\
\text { (IQ) }\end{array}$} & 2 & IQ1 & $\begin{array}{l}\text { Informasi mengenai waktu atas } \\
\text { layanan yang diberikan selalu tepat. }\end{array}$ & 0,852 \\
\hline & & IQ2 & $\begin{array}{l}\text { Informasi mengenai pengiriman dan } \\
\text { lainnya yang akurat dan benar }\end{array}$ & 0,837 \\
\hline \multirow{3}{*}{ Order accuracy } & \multirow[t]{3}{*}{3} & OA1 & $\begin{array}{l}\text { Mengirimkan pesanan sesuai } \\
\text { ketepatan detail purchase order yang } \\
\text { disertai dengan pengiriman order }\end{array}$ & 0,801 \\
\hline & & OA2 & $\begin{array}{l}\text { Ketepatan atas pengiriman ketika } \\
\text { order }\end{array}$ & 0,755 \\
\hline & & OA3 & $\begin{array}{l}\text { Mengirimkan jumlah order sesuai } \\
\text { dengan pesanan }\end{array}$ & 0,762 \\
\hline \multirow{2}{*}{ Timeliness (TL) } & 2 & TL1 & $\begin{array}{l}\text { Produk yang saya pesan dikirimkan } \\
\text { dan sampai dengan cepat }\end{array}$ & 0,848 \\
\hline & & TL2 & $\begin{array}{l}\text { Produk yang saya pesan dikirimkan } \\
\text { dengan waktu yang dijanjikan }\end{array}$ & 0,763 \\
\hline $\begin{array}{l}\text { Quality of Contact } \\
\text { Personel }(Q C P)\end{array}$ & 4 & QCP1 & $\begin{array}{l}\text { Mempunyai transporter yang ramah } \\
\text { dalam pelayanan }\end{array}$ & 0,799 \\
\hline
\end{tabular}




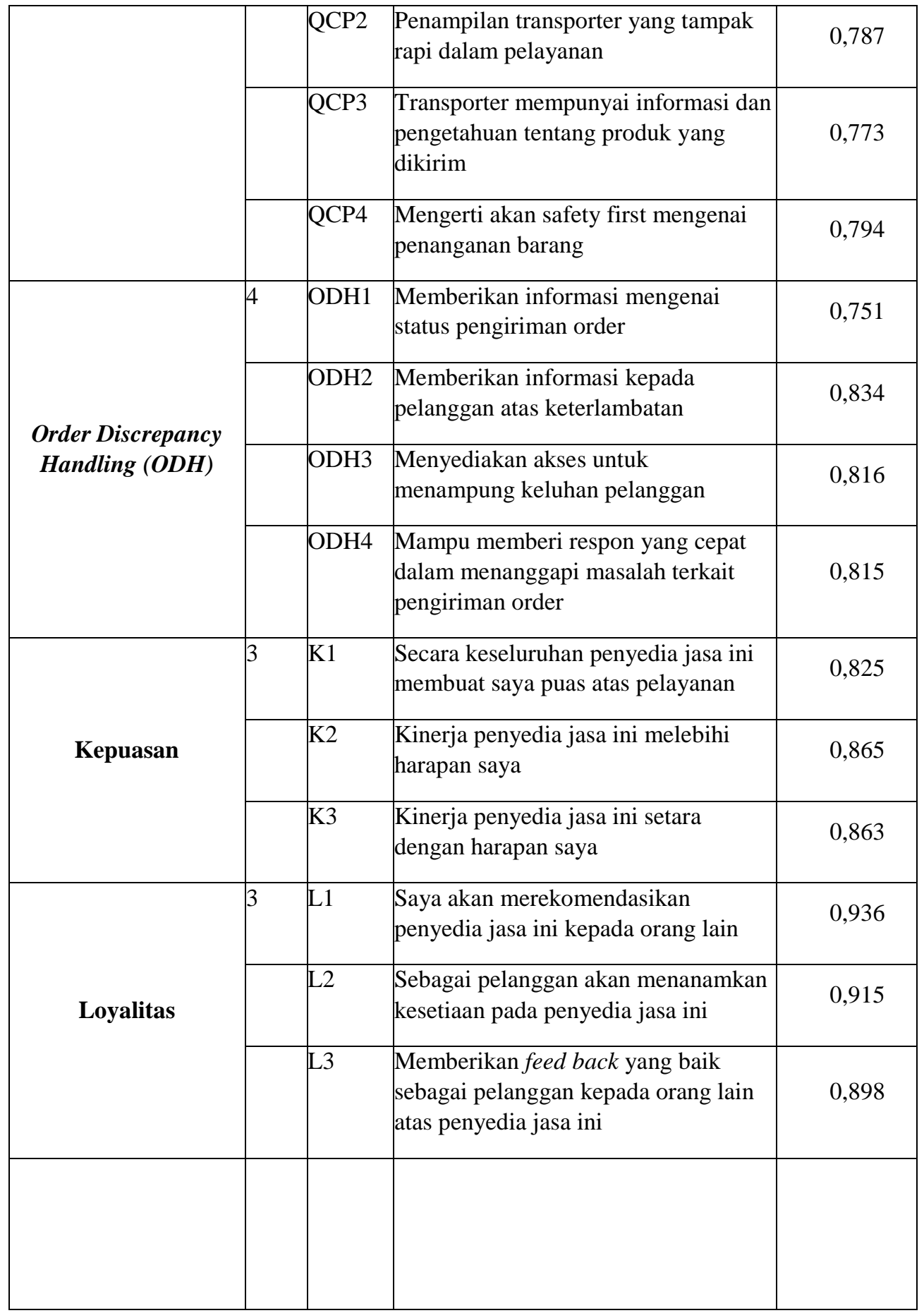

Sumber: Data diolah peneliti tahun 2018

\section{Uji Validitas Konvergen}

Uji validitas konvergen dapat dilihat dari skor nilai AVE dan Communality, masing-masing harus bernilai di atas 0, 50. Berikut merupakan hasil skor nilai AVE dan Communality untuk setiap konstruk:
Tabel 2

Uji Validitas Konvergen

\begin{tabular}{|l|c|c|}
\hline KONSTRUK & $\boldsymbol{A V E}$ & COMMUNALITY \\
\hline $\begin{array}{l}\text { Logistics Service } \\
\text { Quality }\end{array}$ & 0,725 & 0,725 \\
\hline Kepuasan & 0,640 & 0,640 \\
\hline
\end{tabular}




\begin{tabular}{|l|l|l|}
\hline Loyalitas & 0,840 & 0,840 \\
\hline
\end{tabular}

Sumber: Data dioleh oleh peneliti tahun 2018

Tampak pada tabel 2, bahwa semua skor nilai AVE dan Communality memiliki nilai di atas 0, 50. Dengan demikian dapat disimpulkan bahwa konstruk memiliki validitas konvergen yang baik.

\section{Uji Validitas Diskriminan}

Uji validitas diskriminan dinilai berdasarkan cross loading pengukuran dengan konstruknya. Jika korelasi konstruk dengan item pengukuran lebih besar daripada ukuran konstruk lainnya, maka hal tersebut menunjukkan bahwa konstruk laten memprediksi ukuran blok mereka lebih baik dari ukuran pada blok lainnya.

\section{Tabel 3}

Perbandingan Akar AVE dan Korelasi Variabel Laten

\begin{tabular}{|l|l|l|l|l|}
\hline & $\begin{array}{c}\text { AKA } \\
\text { R }\end{array}$ & $\begin{array}{c}\text { Logistic } \\
\text { KONSTR } \\
\text { UK }\end{array}$ & $\begin{array}{c}\text { Kepua } \\
\text { san }\end{array}$ & $\begin{array}{c}\text { Loyal } \\
\text { itas }\end{array}$ \\
\hline $\begin{array}{l}\text { AVE } \\
\text { Service } \\
\text { Quality }\end{array}$ & 0,851 & 1,000 & & \\
\hline $\begin{array}{l}\text { Kepuasan } \\
\text { Quality }\end{array}$ & 0,800 & 0,663 & 1,000 & \\
\hline Loyalitas & 0,916 & 0,768 & 0,663 & 1,000 \\
\hline
\end{tabular}

Sumber: Data diolah oleh peneliti tahun 2018

Berdasarkan pada tabel di atas, dapat disimpulkan bahwa nilai akar AVE hampir seluruhnya lebih tinggi dibandingkan dengan nilai korelasi antara konstruk dengan konstruk lainnya, dan ini menunjukkan semua konstruk dalam model yang diestimasi memenuhi kriteria validitas diskriminan. Nilai AVE dari Logistics Service Quality (Y) pada tabel diatas adalah nilai akarnya sebesar 0,851 . Sedangkan kepuasan (X1) yaitu 0,800 dan loyalitas (X2) yaitu 0,916. Berarti model adalah baik, begitu pula dengan akar AVE yang lain.

\section{Uji Reliabilitas}

Uji reliabilitas dapat dilihat dari nilai Cronbach' Alpha dan nilai Composite Relia-bility. Untuk dapat dikatakan suatu konstruk reliabel, maka nilai Cronbach' Alpha harus >0,6 dan nilai Composite Reliability harus >0,7 (Ghozali, 2014). Perbandingan nilai Cronbach' Alpha dan Composite Reliability dapat dilihat pada tabel 4.37 di bawah ini:

\section{Tabel 4}

\section{Perbandingan Cronbach' Alpha dan Composite Reability}

\begin{tabular}{|l|c|c|}
\hline KONSTRUK & $\begin{array}{c}\text { CRONBACH'S } \\
\text { ALPHA }\end{array}$ & $\begin{array}{c}\text { COMPOSITE } \\
\text { RELIABILITY }\end{array}$ \\
\hline $\begin{array}{l}\text { Logistics } \\
\text { Service Quality }\end{array}$ & 0,810 & 0,887 \\
\hline Kepuasan & 0,960 & 0,964 \\
\hline Loyalti & 0,905 & 0,940 \\
\hline
\end{tabular}

Sumber: Data diolah oleh peneliti tahun 2018

Pada tabel di atas menunjukkan bahwa nilai Cronbach Alpha untuk semua konstruk berada di atas 0,6 dengan nilai terendah 0,810 pada variabel Logistics Service Quality (Y) dan nilai tertinggi 0,960 pada variabel kepuasan (X1). Sementara untuk nilai variabel loyalitas (X2) adalah 0,916. Nilai Composite Reliability untuk semua konstruk adalah di atas 0, 7 yang menunjukkan bahwa semua konstruk pada model yang diestimasi memenuhi kriteria reliabel. Nilai Composite Reliability yang terendah 0,887 pada variabel Logistics Service Quality (Y) dan nilai tertinggi 0,964 pada variabel kepuasan (X1). Sementara untuk nilai variabel loyalitas (X2) adalah 0,940 .

\section{NILAI R SQUARE}

Tabel 5

R Square

\begin{tabular}{|l|c|}
\hline \multicolumn{1}{|c|}{ KONSTRUK } & R SQUARE \\
\hline Kepuasan & 0.639 \\
\hline Loyalitas & 0.303 \\
\hline
\end{tabular}

Sumber: Data diolah oleh peneliti tahun 2018

Tabel di atas menunjukkan bahwa nilai $R$ Square pada variabel Kepuasan (Y1) adalah sebesar 0,639 dan variabel Loyalitas (Y2) adalah sebesar 
0,303. Dapat dikatakan bahwa menunjukkan $63 \%$ variabel kepuasan (Y1) dan 30\% variabel loyalitas (Y2) dapat dipengaruhi oleh variabel Logistics Service Quality (X). Sedangkan sisanya 7\% dipengaruhi oleh variabel lain diluar yang ditentukan dalam penelitian kali ini.

\section{HASIL UJI HIPOTESIS}

Signifikansi parameter yang diestimasi memberikan informasi yang sangat berguna mengenai hubungan antara variabel-variabel penelitian. Dasar yang digunakan dalam menguji hipotesis adalah nilai yang terdapat pada output koefisien jalur berikut ini:

Tabel 6

Hasil Koefisien Jalur dan T-Statistics

\begin{tabular}{|l|c|}
\hline & T Statistik \\
\hline $\begin{array}{l}\text { Logistics Service Quality -> } \\
\text { Kepuasan }\end{array}$ & 15.533 \\
\hline $\begin{array}{l}\text { Logistics Service Quality -> } \\
\text { Loyalitas }\end{array}$ & 2.258 \\
\hline Kepuasan -> Loyalitas & 7.095 \\
\hline
\end{tabular}

Sumber: Data diolah oleh peneliti tahun 2018

Berdasarkan tabel di atas, disimpulkan bahwa hipotesis pertama terdukung karena skor T-Statistics adalah 15.533 diatas nilai T-Table sebesar 1, 64 . Artinya, Logistics Service Quality (Y) secara positif berpengaruh terhadap kepuasan (X1). Begitu pula dengan hipotesis kedua dan ketiga terdukung karena skornya diatas 1,64 yang artinya bahwa lokasi Logistics Service Quality (Y) secara positif berpengaruh terhadap loyalitas (X2) dan terhadap kepuasan (X1) secara positif berpengaruh terhadap loyalitas (X2).

\section{Pengaruh Logistics Service Quality terhadap Kepuasan Pelanggan}

Berdasarkan tabel 6, menunjukkan bahwa hubungan antara variabel Logistics Service Quality terhadap Kepuasan adalah signifikan dengan nilai $T$ statistics berada di atas 1, 64 yaitu sebesar 15.533. Nilai original sample estimate yaitu sebesar 0,159 yang menunjukkan bahwa hubungan antara variabel Logistics Service Quality terhadap Kepuasan adalah positif, dengan hasil demikian hipotesis pertama pada penelitian ini yang menyatakan bahwa "Logistics Service Quality berpengaruh positif terhadap tingkat kepuasan pelanggan dalam penggunaan layanan jasa JNE" positif dan terdukung.

\section{Pengaruh Logistics Service Quality terhadap Loyalitas Pelanggan}

Berdasarkan tabel 6, menunjukkan bahwa hubungan antara variabel Logistics Service Quality terhadap Loyalitas adalah signifikan dengan nilai $T$ statistics berada di atas 1, 64 yaitu sebesar 2.258. Nilai original sample estimate yaitu sebesar 0,662 yang menunjukkan bahwa hubungan antara variabel Logistics Service Quality terhadap Kepuasan adalah positif, dengan hasil demikian hipotesis pertama pada penelitian ini yang menyatakan bahwa "Logistics Service Quality berpengaruh positif terhadap tingkat kepuasan pelanggan dalam penggunaan layanan jasa JNE" positif dan terdukung.

\section{Pengaruh Kepuasan Pelanggan Terhadap Loyalitas Pelanggan}

Berdasarkan tabel 6, menunjukkan bahwa hubungan antara variabel kepuasan pelanggan terhadap loyalitas pelanggan adalah signifikan dengan nilai $T$-statistics berada di atas 1,64 yaitu sebesar 7.095. Nilai original sample estimate yaitu sebesar 0,663 yang menunjukkan bahwa hubungan antara variabel Logistics Service Quality terhadap Kepuasan adalah positif, dengan hasil demikian hipotesis pertama pada penelitian ini yang menyatakan bahwa "Logistics Service Quality berpengaruh positif terhadap tingkat kepuasan pelanggan dalam penggunaan layanan jasa JNE" positif dan terdukung.

\section{SIMPULAN DAN SARAN}

\section{Simpulan}

Berdasarkan pembahasan hasil penelitian diatas, memberikan dan menganalisis pengaruh antara Logistics Service Quality terhadap kepuasan dan loyalitas pelanggan atas layanan jasa JNE. Sampel yang digunakan pada penelitian ini adalah mahasiswa jurusan ruang lingkup manajemen bisnis yang berasal dari berbagai perguruan tinggi se Kota Batam. Hasil dari penelitian ini menunjukkan bahwa ketiga hipotesis yang diajukan adalah terdukung dan signifikan. Hasil penelitian ini menunjukkan bahwa:

a. Logistics Service Quality berpengaruh positif dan signifikan terhadap tingkat kepuasan pelanggan dalam penggunaan layanan jasa. Dapat dikatakan bahwa Logistics Service Quality mampu memberikan pengaruh yang positif terhadap tingkat kepuasan pada pelanggan. 
b. Logistics Service Quality berpengaruh positif dan signifikan terhadap tingkat loyalitas pelanggan dalam penggunaan layanan jasa. Dapat dikatakan bahwa Logistics Service Quality mampu memberikan pengaruh yang positif terhadap tingkat loyalitas pada pelanggan.

c. Kepuasan pelanggan berpengaruh positif dan signifikan terhadap tingkat loyalitas pelanggan dalam penggunaan layanan jasa. Dapat dikatakan bahwa rasa kepuasan dari pelanggan mampu memberikan pengaruh positif terhadap tingkat loyalitas dari pelanggan.

\section{Saran}

Peneliti menyarankan agar penelitian selanjutnya dapat menggunakan lebih dari satu penyedia layanan jasa logistik seperti Pos Indonesia, JNT, TIKI dan lainnya agar dapat membandingkan tingkat kepuasan dan loyalitas pada pelanggan. Memilih sampel yang lebih luas lagi cakupannya untuk dijadikan responden pada penelitian. Menambahkan jumlah variabel pada penelitian selanjutnya.

\section{KETERBATASAN}

Penelitian ini hanya menggunakan sampel mahasiswa jurusan pada ruang lingkup manajemen bisnis yang berasal dari berbagai di perguruan tinggi se Kota Batam. Selain itu, sampel yang digunakan hanya satu penyedia layanan jasa logistik yaitu JNE, sehingga pada penelitian ini tidak dapat membandingkan dengan penyedia layanan jasa logistik yang lainnya.

\section{DAFTAR PUSTAKA}

A. Adrian Micu, K. a. (2013). Implication Of Logistic Service Quality On The Satisfaction Level And Retention Rate Of An E-Commerce Retailer's Customer. Economic Computation and Economic Cybernetics Studies, vol. 47, issue 2, pp. 147-155.

B. Calyptra. (2014). Pengaruh Logistik Service Quality Terhadap Satisfaction dan Loyalty Di PT Tiki Jalur Nugraha Eka Kurir. Jurnal Ilmiah Mahasiswa Universitas Surabaya, Vol.3 No.2.
C. Ho, Y. J. (2012). Logistic service quality among courier services in Malaysia. . International Conference on Economics, Business Innovation IPEDR, vol.38. IACSIT Press, Singapore.

D. Jogiyanto, H. (2011). Konsep dan Aplikasi Structural Equation Modeling (SEM) Berbasis Varian dalam Penelitian Bisnis. Yogyakarta: STIM YKPN.

E. Kotelr, P. \&. (2007). Manajemen Pemasaran jilid 1 edisi 12. PT Indeks kelompok Gramedia.

F. Kotler, P. (2002). Manajemen Pemasaran di Indonesia : Analisis, Perencanaan, Implementasi dan Pengendalian. Jakarta: Salemba Empat.

G. Kotler, P. (2003). Marketing Management 11th Edition. New Jersey: Prentice Hall Int'l.

H. Lupiyoadi. (2001). Manajemen Pemasaran Jasa teori dan Praktek. Jakarta: Salemba Empat.

I. Raymond Hendry, Y. E. (2015). Pengaruh Logistic Service Quality Terhadap Kepuasan Dan Loyalitas Konsumen Kentucky Fried Chicken di Surabaya.

J. Richard, G. (2002). Mengukur Kepuasan Pelanggan. Jakarta: PPM.

K. Saura, e. a. (2008). Logistics Service Quality: a new way to loyalty. Industrial Management \& Data Systems, Vol. 108, No. 5, pp.650668.

L.Spiros Gounaris, S. D. (2010). An examination o the effects of service quality and satisfaction on customers' behavioral intentions in eshopping. Journal of services marketing 24/2, 142-156.

M. Sugiyono. (2017). Metode Penelitian Kuantitatif, Kualitatif, dan R\&D. Bandung: Alfabeta, CV

M. Sutrisna. (2002). Perilaku konsumen dan komunikasi pemasaran. Bandung: Remaja Rosdakarya.

N. Tjiptono. (2004). Pemasaran Jasa. Malang: Bayumedia Publishing.

O. Tjiptono, F. \&. (2005). Service, Quality and Satisfaction. Yogyakarta: Penerbit Andi.

P. Tjiptono, F. (2001). Strategi Pemasaran Edisi Pertama. Yogyakarta: Andi Ofset. 
Q. Tjiptono, F. (2007). Strategi Pemasaran Edisi Pertama. Yogyakarta: Andi Ofset.

R. Tseng, S.-M. (2016). Knowledge management capability, customer relationship management, and servise quality. Journal of Enterprise Information Management, Vol. 29 lss 2 pp. 